\section{Compassion and Progress}

\author{
Bert Fellows, MA
}

As I sit here thinking about what to write, a thought occurs: compassion and progress. Entering this new millennium with better health care, improved lifestyles and techno-medical advancements, the life span is likely to increase, and with it age related maladies and their companion; pain. As a result, the preeminent specialty in the next century may well be interventional pain medicine. It therefore behooves us in our self-imposed role as mid-wives to this new speciality to ensure a safe and sound delivery and a nurturing environment in which to grow. Growth is progress, but sometimes it occurs in a random fashion so we need to apply our scientific and clinical skills to guide this growth. Compassion will be the most important ingredient in this process: compassion for our predecessors who have paved the way into the $21^{\text {ST }}$ century; for each other as we struggle with our new identity; and most of all for our patients who desperately need a revolution in pain care interventions. Without compassion, our progressive efforts will ring hollow. Without progress, our compassion will go unheeded. And now my thought becomes clearer and I suggest we subtitle our journal: the voice of compassion and progress in interventional pain medicine. Let me know what you think. Now on to this issue.

After a rousing letter from the president, we quickly enter the frequently undiagnosed world of internal disc disruption where Drs. Sehgal and Fortin take us on a guided tour from the history and clinical presentation to treatment.

We then move on to examine the inability - yes, the inability - of the clinical picture to characterize pain from facet joints by Manchikanti et al, an article sure to make all diagnosticians question their prejudices, assumptions, and long established habits. The next article, by Lloyd Saberski, is inspiring, though it is preliminary. Dr. Saberski draws our attention in his pilot study to the importance of interventional pain medicine alternatives when compared to surgery. The implications of his findings are dramatic, though not yet proven. We need to heed his call for a

Mr. Fellows is a Psychologist at Pain Management Center of Paducah and Editor of Pain Physician. Address correspondence: Bert Fellows, MA, Pain Management Center of Paducah, 2831 Lone Oak Road, Paducah, KY 42003 prospective study to verify these findings and provide concrete outcomes and cost saving evidence with which to persuade HCFA and other $3^{\text {rd }}$ party payers. The Epidemiology of Low Back Pain, a subject full of surprises and challenges is presented in a topical review. The similarly fascinating subject of headache secondary to extracranial sources and its management, emphasizes the number of options available for interventional pain practitioners. This is definitely welcome news for the victims of intractable headache who have all but been given up on - those poor souls who haunt the ER's until they are finally labeled addicts or "crocks". We will also take a look at the very important subject of Impairment Evaluations in Pain Management and then, not one to leave things untidy, Laxmaiah Manchikanti, returns for one final article in this issue - an article devoted to one of his favorite subjects, the Appropriate Documentation, Billing, and Coding of Interventional Pain Procedures, a subject which must be mastered if this new speciality is to survive. Helping us to survive, William A. Sarraille, Allison Weber Shuren, and Jeff Peters, our colleagues and counsel from Arent Fox, have once again provided us with the Washington News and Health Law, this time focusing on the compliance Guidelines which the office of the Inspector General is soon to release.

We are now circulating the journal to over 1400 medical school and hospital libraries, as well as to almost 4000 interventional pain physicians and 60 fellowship programs. Please consider making a contribution to the journal.

Many thanks to all of you who have already contributed to the journal and to the organization, and thanks to our support staff, Vidyasagar Pampati, Michelle Powell, Kevin Court, Ben Lawrence, Diane Dunmyer, Tonie Hatton and Paula Benson. They have worked harder than ever to get this issue out and their work also goes into our website at www.aopma.org.

Make your plans to attend our Second Annual Meeting in Washington, D.C. on September 15-16-17, 2000. We will meet again this year at the Sheraton National Hotel. You will not be disappointed. Make your reservations now. You will be receiving more details in the next few months. Until then, remember that together we can make a difference. 